\title{
Helen Whelton: 'It is difficult to imagine the population's decay levels without fluoridation'
}

Please send any ideas for feature articles for consideration to:

Ruth Doherty,

Managing Editor,

British Dental Journal,

The Macmillan Building,

4-6 Crinan Street,

London,

N1 9XW

Email: r.doherty@nature.com

Helen Whelton, new President of the IADR, on fluoridation, inequalities in public health and the condition of Irish teeth.

What do you feel is the biggest dental public health challenge in the world today?

Reform of public policy in favour of social justice is the biggest challenge facing not just dental public health but public health at large. All sectors of the community stand to benefit from greater social justice and we can't afford to ignore the threat of increasing inequalities in countries in deep economic recession. If we allow the social divide to grow, social cohesion will suffer, civil unrest will grow and society will see an increase in crime.

We are really good at preventing oral diseases for the middle and upper classes but we know that what works well for middle class people doesn't necessarily translate for disadvantaged groups with the most disease. We are a long way from cracking that nut so we can't afford to be too self-congratulatory about our progress. Future research efforts in this area need to focus on interventions to keep people healthy, which integrate promotion of oral health with general health. The IADR Global Oral Health Inequalities Research Agenda represents an important step in tackling the challenges posed by inequalities in oral health.

\section{What are the main differences between the oral health landscape in Ireland versus the UK?}

There are three differences that come to mind, the first is a legislative difference regarding water fluoridation; the second

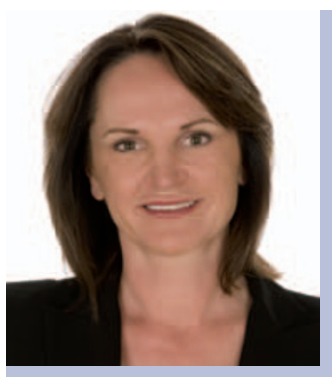

Professor Helen Whelton assumes the role of President of the International Association for Dental Research in March 2013. Helen is based at University College Cork (UCC) in Ireland where she is Vice Head of the College of Medicine and Health and Professor of Dental Public Health and Preventive Dentistry. She is also the Director of the Oral Health Services Research Centre in the university. Helen qualified with a BDS from UCC in 1980 and after three years in NHS dentistry and public dental service she took up a position as a researcher in her alma mater. She then completed her PhD in 1989 and a Masters in Dental Public Health in 1999. She was appointed a senior lecturer in 1998 and professor in 2007. Helen has been the principal investigator of a number of large national surveys of oral health in Ireland including the first all Ireland children's oral health survey, a national survey of oral health of adults with special needs and an adult oral health survey. She is currently leading a large study to evaluate the impact on children's oral health of the 2007 reduction of the level of fluoride in the water. Outside of dentistry Helen has served on the board of the Irish Health Research Board, the National Obesity Task Force and the Irish Women's Health Council.

is the policy difference in the delivery of dental services; and the third is the approach to promoting oral health.

In Ireland we have mandatory national water fluoridation which serves 73\% of the population whereas in the UK legislation enables councils to fluoridate the water (serving about 10\% of the UK population). Water fluoridation is a major component of Irish oral health policy, particularly because international comparisons show that the Irish have a sweeter tooth than people in most other countries (except perhaps the Scottish!) and that there is plenty of room for improvement in brushing habits.

Many children in Ireland do not go to the dentist until they are seen at age 7-8 by the public dental service. By comparison, the NHS service encourages early and frequent attendance of infants at general dental practice. Thus the policies pertaining to availability of and access to preventive services and dental care are very different.

The professionalisation of public health as a specialty in the UK, the availability of excellent training schemes and the deployment of consultants in dental public health have been accompanied by improvements in oral health that have outpaced those in Ireland and conferred a huge advantage on the British population in terms of improved wellbeing. The Scottish Childsmile programme is an example of the tremendous success that can be achieved in a climate of support for dental public health. In contrast, the under development of the discipline in Ireland is manifest by the lack of specialists or consultants in dental public health and the absence of a Chief Dental Officer for almost a decade.

Some of the challenges in Ireland are due to the lack of an economy of scale; 
with a population of 4.5 million it is difficult to implement the kinds of structures one can justify in a country such as England for example, with a population of 53 million. However, professional input to national policy needs to be maintained. In Ireland recent years have seen a worrying diminution of the scale and scope of state-funded dental schemes, the impact of which is as yet unknown. The future is looking brighter though as we graduate a growing number of skilled dental public health advocates from our masters and $\mathrm{PhD}$ programmes in UCC. In addition, Dympna Kavanagh, a consultant in dental public health has been appointed to a leadership position in the health service. She is a powerful advocate for dental public health and is already having a positive impact.

\section{What attracted you to epidemiol- ogy and dental public health?}

The opportunity to make a difference on a grand scale. I really like to be able to see the big picture. When I worked in the school dental service I used to wonder how much difference water fluoridation was making, what level of untreated disease there was and how I could monitor my impact on oral health at the population level. I was convinced that we could motivate dentists much more if we could give them a map of their impact. It is really important to me to make the best use of available resources to prevent oral diseases and provide effective and efficient oral health services. Smart oral health policy should be based on all of the available information including service data and research evidence.

I was very lucky to find my way into epidemiology. In the early 1980s there were very few jobs in dental research in Ireland but in 1983 I was really excited to be employed as a researcher on the Irish National Survey of Children's Oral Health led by Denis O'Mullane at the Dental School and Hospital in UCC.

It is a huge privilege to work at something I love so much, and to lead a team of people whose company I enjoy and for whom I have the utmost respect.

\section{If you were Taoiseach what would you use the power to do?}

I would facilitate the brightest and most creative people from all over the world to come to work and live in Ireland and make us the Silicon Valley of Europe. We are in the height of a technology revolution and Ireland is already a global hub for technology development. Our young population gives us a strategic competitive advantage in this arena so as well as bringing in good people I would ensure that our own children are equipped to take full advantage of Ireland's position as a technology hub. To do this, I would add coding or computer programming to the basic skills acquired by our children. The Irish led international Coder Dojo movement shows the potential for such an initiative. Our young army of creative programmers would code our way through economic recovery and out of recession.

A high quality health service and a healthy population is essential for a thriving economy, so the second thing I would do would be to reform the public service with a focus on skilful management, maintenance of health with a far reaching health promotion strategy and production of better health outcomes.

\section{What motivated you to choose an academic path over a clinical one?}

It wasn't an ambition when I was an undergraduate student. I spent a few years between the NHS in London and Public Dental Service in Ireland. I really enjoyed working in the NHS; I was an associate at a wonderful practice in Sydenham next door to St Christopher's Hospice and we used to provide care for the patients there, which was an aspect of the work that I found very rewarding. I might have continued on that path but wedding plans brought me back to Cork to my husband, Frank, who was at that point establishing his own general dental practice. When I came home I started to work in the Public Dental Service, I used to work in some rural clinics and enjoyed a fantastic relationship with the local communities. However, when an opportunity arose to work in dental research I knew it was absolutely right for me. I haven't looked back since my first research job.

\section{What has been the impact of water fluoridation in Ireland?}

Quite simply it is difficult to imagine the state of the population's decay levels without it. Having run four large scale national and 11 regional epidemiological surveys to monitor the effects of water fluoridation in Ireland I can say, with confidence, that decay levels are much lower among the 73\% of the population living in fluoridated areas compared with those in non-fluoridated areas. One of our studies involved 20,000 children in the Republic and Northern Ireland; we found 40\% lower caries levels among 15-year-olds living in fluoridated areas of the Republic compared with those living in Northern Ireland. Within the Republic of Ireland caries levels were 32\% lower among those living in fluoridated areas. The differences still existed when we controlled for social class and tooth brushing. Our work has demonstrated benefits for adults too; many Irish adults have had over 50 years of water fluoridation.

We have monitored fluorosis levels since 1984. In 2002, in response to an increasing fluorosis prevalence which showed up in our studies, the Department of Health issued advice to parents of young children not to start using toothpaste on their children's teeth until age two and to use a pea sized amount after that until age seven. In addition, in 2007 they lowered the level of fluoride in the water. Subsequent research by one of our PhD students demonstrated that the levels of fluorosis we see in Ireland are generally not of aesthetic concern. My team has recently received funding to research the impact of the policy changes on the levels of caries and fluorosis in children in Ireland. This study is due to commence in September 2013.

There is no doubt in my mind that some countries have more to gain from fluoridation than others. Countries with infrastructures supporting healthy eating from infancy, with well-developed public health systems and appropriate use of fluoride toothpaste may have little to gain from water fluoridation. However, successive international comparisons of health behaviour and lifestyles by WHO reveal that Irish behaviours are more consistent with those of countries with much higher caries levels, so, water fluoridation continues to play an important role in oral health.

\section{What living person do you most admire and why?}

Something I admire in our profession, 
which makes me proud to be a dentist but is rarely mentioned, is the level of the generosity of practitioners in providing 'pro bono' treatment to members of the public who are unable to pay. I was amazed at the level of such activity we found during the course of some recent interviews about provision of dental care to the elderly population in general dental practice. Many dentists provide free or below cost treatment in cases where hardship is evident. Although it isn't an answer to our public health challenges, it is a heartening reflection of the profession.

On the international front one of the people I find truly inspirational is Aung San Suu Kyi, the iconic leader of the Myanmar pro-democracy movement. What an amazing woman. She has been incredibly selfless in the pursuit of human rights and I have huge admiration for her personal qualities including her leadership, determination, generosity of spirit, strength of character and her dignity. It is remarkable to see what she has achieved through unwavering peaceful protest. Her positive attitude and ability to focus on the future rather than the past are powerful traits in a leader.

\section{If you had unlimited funding to research one problem what would it be?}

In terms of oral health I would like to tackle the most common oral diseases, caries and periodontal disease. Imagine how the oral health landscape would change if we could develop a passive way of eliminating these diseases. Both are bacterial diseases brought about by an adverse shift in the oral flora. Given unlimited funding I would research an effective means of developing and maintaining a health promoting oral flora. An example of a passive means would be a dietary additive such as an effective prebiotic or probiotic to commonly consumed products like bread. Identification of the effective agent is the first challenge.

\section{What has been the biggest challenge to date in your career?}

Balancing home and work life. If it weren't for a very supportive and tolerant partner and an excellent childminder my career would have gone nowhere. Having an outstanding mentor who pushed and encouraged me at every turn was also a huge advantage. However, it wasn't easy and I often wondered whether I was doing the right thing in terms of my children. It was only as they got older that I began to see the benefits in terms of my relationship with them and my ability to draw on my own life experience to support them in various contexts. I once asked them if they would like me to stay at home and I got a rapid and resounding NO! Different pathways suit different people and for me pursuing a career was best.

\section{As President-elect of the IADR, what would you like to achieve in your term?}

I am honoured and proud to be elected as president of this robust and vibrant research organisation and to follow in the footsteps of so many outstanding leaders in dental research who have made the IADR what it is today. The largest dental research organisation in the world, the IADR has an outstanding global headquarters team directed by Dr Christopher Fox and based in Washington, D.C. I will be president from March 2013 to July 2014 and I have three main goals for my presidency relating to membership, promoting the creation of knowledge and tackling inequalities in oral health.

The mission of IADR is "to advance research and increase knowledge for the improvement of oral health worldwide'. Under my leadership I want to see IADR membership grow in established economies as well as in developing countries.

IADR meetings offer unique networking opportunities. I want all early researchers to experience the fantastic buzz of an IADR meeting like I did at my first meeting in The Hague. I still remember the excitement of seeing so much research presented in such an accessible format and being able to engage with the authors of papers that I had read.

The current technological era has brought about an information explosion. As the leading dental research organisation the IADR is uniquely positioned to ensure that the technology revolution is harnessed and applied to the generation of new knowledge and evidence to promote oral health. During my term I would like to build on the current engagement with industry, state agencies and practice, and develop greater involvement of these groups in IADR so that we can promote the development and sharing of evidence on effective therapies in practice.

Finally, as a global organisation IADR is uniquely placed to foster and promote research on effective interventions to address inequalities in oral health. Despite all of the rhetoric on this subject, progress has been slow and there exists vast differences in the distribution of health and disease for both oral health and general health. The IADR under the leadership of successive presidents starting with David Williams through to my immediate predecessor, Mary MacDougall, developed an agenda for oral health inequalities research, a call to action for researchers, governments and funding agencies and a research network to support its implementation. I too will promote and advance this agenda through advocacy during my presidency.

\section{What do you think is the best model of healthcare provision?}

There are two traits I would look for in a good model of healthcare provision, the first being a socially just model that promotes general health and oral health among the less well-off and makes care universally available, accessible and acceptable. Better integration of oral health with general health would be helpful in developing such a model.

The second characteristic of the ideal model would be a system that rewards prevention more than treatment. As a profession we need to start seeing ourselves as oral physicians rather than oral surgeons. It would make a big difference if the general public valued our successes in prevention as much as they value treatment. Interaction with children and their parents from infancy to maintain health and prevent disease is essential. We need to make prevention more visible. We have been talking about reorienting services from treatment to prevention since before the WHO Ottawa Charter in 1986 but we're not there yet.

Interview by Ruth Doherty, $B D J$ Managing Editor 